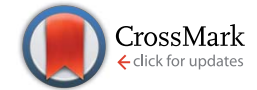

Cite this: RSC Adv., 2014, 4, 52598
Received 30th July 2014 Accepted 9th October 2014

DOI: $10.1039 / c 4 r a 07848 a$

www.rsc.org/advances

\section{Electrospinning: a facile technique for fabricating polymeric nanofibers doped with carbon nanotubes and metallic nanoparticles for sensor applications}

\begin{abstract}
Zhiqiang Su, ${ }^{\star a}$ Junwei Ding ${ }^{a}$ and Gang Wei*b
The increased interest in electrospinning (ES) and its recent applications for fabrication of sensors and biosensors is driven by the development of materials science and nanotechnology. Compared with other fabrication processes, ES is versatile and superior for producing and constructing ordered and complex nanofibrous materials. The introduction of carbon nanotubes (CNTs) and metallic nanoparticles (MNPs) into the electrospun polymeric nanofibers (NFs) extends their potential applications as electrical and electrochemical sensors and biosensors. In this review, we summarize the recent progress using the ES technique to fabricate different polymeric NFs doped with CNTs and various MNPs, as well as their applications for detecting alcohols, $\mathrm{H}_{2} \mathrm{~S}, \mathrm{H}_{2}$, glucose, $\mathrm{H}_{2} \mathrm{O}_{2}$, and urea. The fabrication, intrinsic fundamentals, and optimization design of the sensors were introduced and discussed in detail. In addition, the improvements and challenges of ES techniques were mentioned. It is expected that this review will promote development in the ES field and guide studies to create nanofibrous hybrid materials as novel sensors and biosensors.
\end{abstract}

\section{Introduction}

Electrospinning (ES) is a technique to spin polymeric fibers and nanofibers (NFs) by using electrostatic forces, which was firstly introduced by Anton Formhals in $1934 .{ }^{1}$ However, it did not

${ }^{a}$ Beijing Key Laboratory on Preparation and Processing of Novel Polymeric Materials, Beijing University of Chemical Technology, 100029 Beijing, China. E-mail: suzq@ mail.buct.edu.cn

${ }^{b}$ Faculty of Production Engineering, University of Bremen, D-28359 Bremen, Germany. E-mail:wei@uni-bremen.de; Fax:+49 42121864599 attract much attention until the 1990s. The neglect of this technique by researchers is ascribed to two possible reasons. One reason is that the high-voltage electrostatic generation technique was not very mature in the earlier years, and the other is that the small-size effect of the electrospun NFs had not been understood before the development of nanotechnology. With the help of nanotechnology, ES technique was recovered by Darrell et al. in 1996, who found that it is a very simple and powerful technique to generate ultrafine polymeric fibers with diameters ranging from micrometer to nanometer. ${ }^{2}$ Since then,

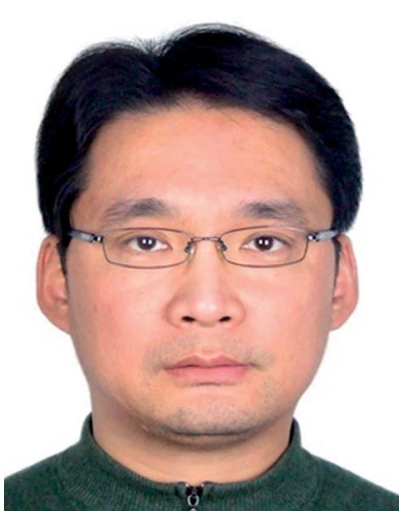

Zhiqiang Su is a Professor at Beijing University of Chemical Technology, China. His research is focused on nanohybrids, biomedical materials, polymer materials, biosensors, and bioelectronics. So far, he has published more than 60 papers in international peer reviewed journals. The papers have been cited nearly 400 times with an $h$ index of 14 .

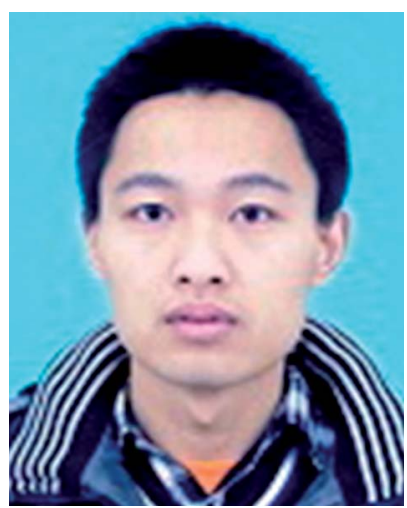

Junwei Ding is currently a Master student supervised by Prof. Su at Beijing University of Chemical Technology, China. His scientific interests are focused on functional materials by electrospinning, electrochemical biosensors, and organic-inorganic hybrid nanomaterials. 
ES technique has been widely utilized for academic research and industry applications.

The standard setup for ES consists of a spinneret with a metallic needle, a syringe pump, a high-voltage power supply, and a grounded collector, as shown in Fig. 1a. A solution of polymer, sol-gel, or composite is loaded into the syringe and this viscous liquid is driven to the needle tip by a syringe pump, forming a droplet at the tip. ${ }^{3-5}$ When a high voltage is applied to the metallic needle, the droplet is first stretched into a structure called Taylor cone and finally into an electrified jet. The jet is then elongated and whipped continuously by electrostatic repulsion until it is deposited onto the collector. The elongation with instable bending results in the formation of uniform fibers and NFs.

Previously we made a new promotion of ES technique by adding a pair of parallel auxiliary electrodes and a mobile platform to get not only well-oriented NF alignment but also controllable NF placement in the large-scale NF mats for extensive applications in electrochemical sensing. ${ }^{6-9}$ Fig. $1 \mathrm{~b}$ and c show the optical image and schematic presentation of our home-made ES apparatus. The rotating drum collector, the positive high-voltage supply, and the liquid propulsion system

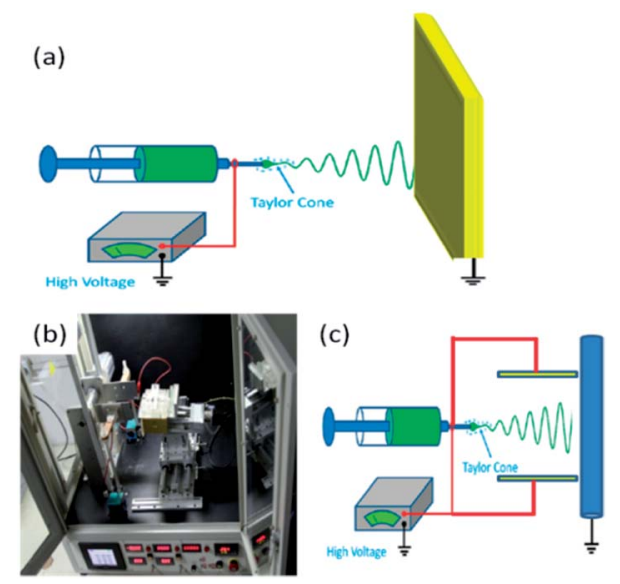

Fig. 1 (a) Schematic diagram of ES technique; (b) photograph of the home-made ES apparatus and (c) schematic presentation.

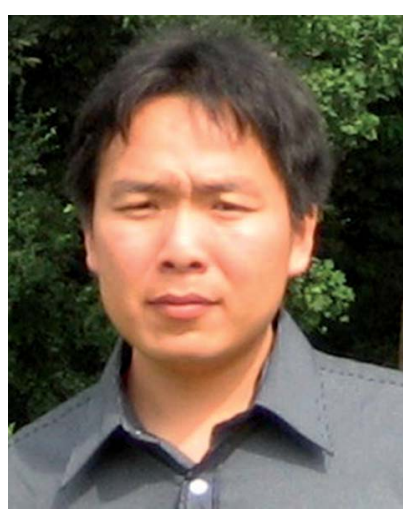

Gang Wei is currently a postdoctoral researcher and group leader in the Hybrid Materials Interfaces Group at the University of Bremen, Germany. His research interests include carbon-based nanomaterials, nanofibrous biomaterials, biosensors, and single-molecule force spectroscopy. He has published 55 papers in international peer reviewed journals and the published papers have been cited nearly 800 times with an h-index of 18. are components of the standard ES configurations. During a conventional ES process, the polymer jet exhibits bending instabilities due to the repulsive forces between the charges carried within the jet, so that the electrospun fibers always result in a random orientation, which restricted the applications of ES technique for preparing new functional materials. To solve this problem, we added a pair of parallel auxiliary electrodes between the spinneret and drum collector, and replaced the common rotating drum collector with a high speed one. ${ }^{6}$ The two symmetric, rectangular, and auxiliary aluminum electrodes were operated at a high voltage of the same polarity as the needle but with an adjustable potential controlled by another independent high-voltage power supply. The alignment of polymeric NFs can be improved by constraining the bending instability, which is thought to be the main reason to cause random orientation. Besides NF mesh without orientation, other NF structures (e.g., parallel and crossed fiber arrays, helical or wavy fibers, twisted fiber yarns, patterned fiber web, and 3D fibrous stacks) can also be fabricated with the modified ES technique. ${ }^{6,10-14}$

In the past years, a variety of microfibers and NFs from a remarkable range of organic and inorganic materials have been prepared with ES technique successfully. The specific physical and chemical properties of the created fibers make them very versatile for different applications such as optoelectronics, sensors, catalysis, textiles, filters, fiber reinforcement, tissue engineering, drug delivery, and wound healing..$^{8,9,15-22}$ There are a variety of parameters that influence the morphology and diameter of the electrospun fibers, such as the intrinsic properties of solution, operational conditions, humidity, and temperature.

Carbon nanotubes (CNTs) have attracted great attentions due to their excellent mechanical, electrical, chemical, and thermal properties..$^{23,24}$ By introducing a small amount of CNTs, either in the form of small bundles or individuals, into the electrospun polymeric NFs, the mechanical strength, conductivity, and thermal resistance of the final NF-CNT composites can be obviously improved compared to those of the pristine polymeric NFs. ${ }^{25,26}$ Therefore, the idea of dispersing and aligning CNTs in a NF matrix to form composite materials seems to be very promising. CNTs offer unique advantages including enhanced electronic properties, a large edge plane/basal plane ratio, and rapid electrode kinetics, making them very useful for fabricating functional devices and sensors. ${ }^{27,28}$ It is well known that the CNT-based sensors and biosensors generally have higher sensitivities, lower detection limit, and faster electron transfer kinetics than the traditional carbon electrodes. ${ }^{29}$ Nanoparticles (NPs), especially metallic nanoparticles (MNPs) with nanoscale size, have unique electrical, optical, magnetic, and chemical properties, and their potential applications in the fields of nanotechnology, materials science, biomedical engineering, and tissue engineering have been widely explored. ${ }^{30-34}$ It is well known that the size and shape of NPs, as well as the hybridization of NPs with other components are the key factors for determining, revealing and enhancing the functions of NPbased materials. ${ }^{33,35-37}$ In principle, one can accurately tune the physical and chemical properties of NPs by controlling any one 
of these parameters, but the flexibility and scope of change are highly sensitive to some specific parameters. For instance, gold (Au) NPs have size-dependent surface plasmon resonance (SPR) property and generally exhibit visible SPR absorption, whereas $\mathrm{Au}$ nanorods, nanocage and hollow nanospheres own strong near-infrared (NIR) absorption. ${ }^{38-40}$ These novel $\mathrm{Au}$ nanostructures with NIR absorption are very important for photothermal therapy and bio-imaging in the NIR region because blood and soft tissue in the NIR region are relatively transparent, therefore the collateral damage to surrounding healthy tissue is minimized. Platinum (Pt) NPs with high-index facets or multi-compositions have been proven to exhibit higher electrocatalytic activities toward the oxidation and oxygen reduction reactions of small molecules than some commercial catalysts. $^{\text {41-43 }}$ Silver (Ag) NPs with proper size, complex sharp, more edges and corners have higher surface-enhanced Raman scattering activity than the spherical Ag NPs. ${ }^{44}$ Therefore, the control of these pivotal parameters of NPs makes it possible to enhance their potential applications in catalysis, electronics, photography, photonics, sensing, imaging, medicine and information storage. ${ }^{30-33,35,37,39,43}$

Sensing with nano-system is a rising interdisciplinary topic, which combines the advantages of traditional analytical techniques (e.g., high sensitivity, rapid detection, and low cost, etc.) with the unique electronic, optical, magnetic, mechanical, and catalytic properties of NPs. ${ }^{45,46}$ NP-based electro-analytical techniques show great potentials to construct different platforms for chemical sensing and biosensing. NPs can effectively catalyze the redox processes of some molecules due to their high conductivity, large surface area, and unique surface property, permitting an obvious improvement of analytical performances with lower detection limit and shorter deposition time. ${ }^{47,48}$

The interest in ES technique to fabricate functional nanomaterials for sensing is growing fast. A survey of open publications related with "electrospinning" and "sensor" in the past 10 years with SciFinder Scholar was performed and the result is shown in Fig. 2. Meanwhile, the applications of the electrospun nanomaterials for fabricating electrochemical sensors and

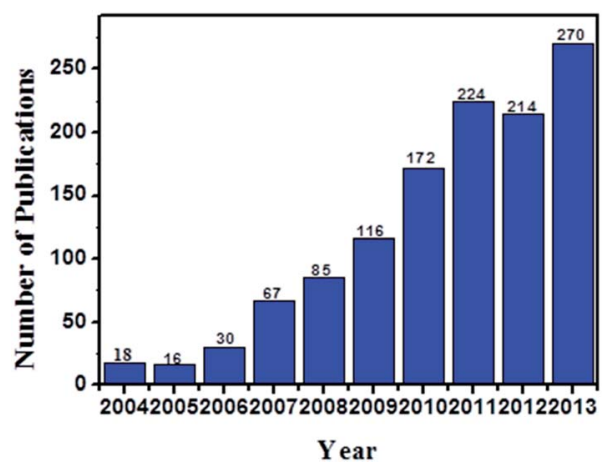

Fig. 2 Comparison of the annual number of scientific publications with the keywords of "electrospinning" and "sensor", as searched by SciFinder Scholar. There are already 159 related publications before July 17, 2014. biosensors are still at an early but promising stage. In this review, we outline the representative progress in fabricating polymeric NFs doped with CNTs and NPs by ES technique. The sensor applications of the electrospun NF-CNT, NF-MNP, and NF-CNT-MNP composites were introduced in detail. Finally, some personal perspectives in this area were given.

\section{Electrospun polymer NFs doped with CNTs for electrochemical sensing}

\subsection{Electrospun polymer NFs}

Electrospun NFs are featured with very small diameters, extremely long length, large surface area per unit mass, and small pore size. Fibers with different morphologies, like uniaxially and biaxially aligned NF meshes, ${ }^{6}$ ribbon, ${ }^{49}$ porous fibers, ${ }^{50}$ Necklace-like, ${ }^{51}$ nanowebs, ${ }^{52}$ hollow, ${ }^{53}$ nanowire-inmicrotube, ${ }^{54}$ and multichannel tubular, ${ }^{55}$ have been created by controlling the ES parameters (Fig. 3). For example, recently we reported the orientation of poly(ethylene oxide) (PEO) NFs by an advanced ES technique. ${ }^{6}$ Fig. $3 \mathrm{a}$ and $\mathrm{b}$ show the uniaxially and biaxially oriented NF assemblies created by our home-made apparatus, respectively. Furthermore, we created both uniaxially oriented NF mats with different NF density and biaxially oriented NF mats with different layers by adjusting the spinning time, movement speed, and auxiliary voltage.

Meanwhile, ultrathin polystyrene (PS) fibers with porous structures on their surfaces have been successfully fabricated by Zhao's group. ${ }^{50}$ The porous structure distributed on the fibrous surfaces was thought to be caused by the volatile solvent. Also, they obtained knotted fibers by coaxial ES. ${ }^{56}$ In their study, PS

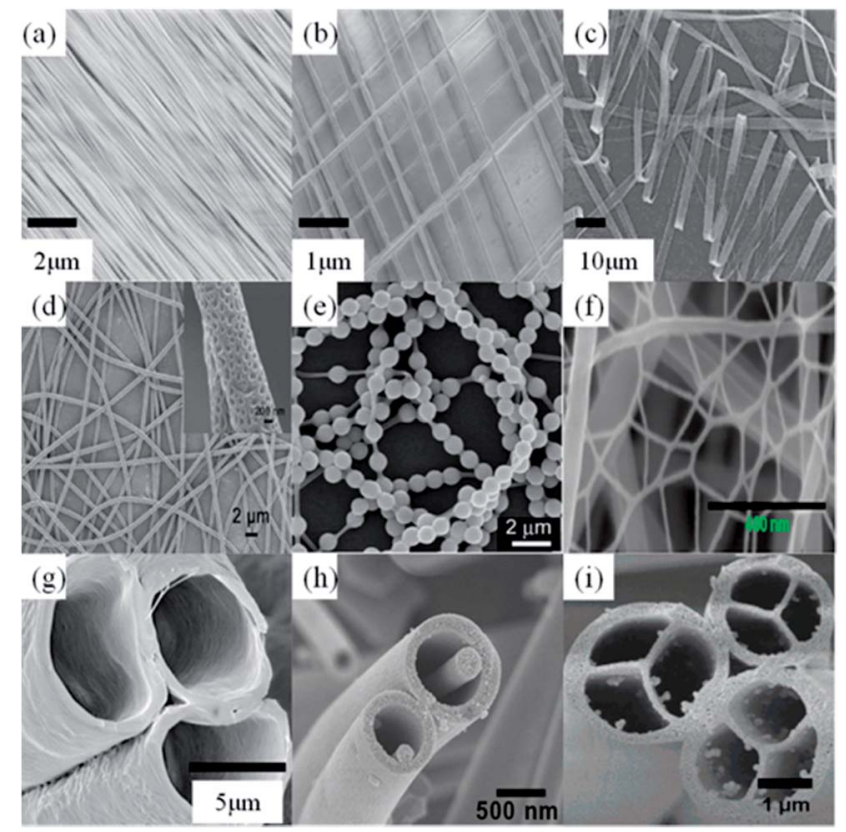

Fig. 3 Different morphologies of electrospun polymer fibers: (a) uniaxially aligned, (b) biaxially oriented, (c) ribbon, (d) porous fibers, (e) Necklace-like, (f) nanowebs, (g) hollow, (h) nanowire-in-microtube, and (i) multichannel tubular. 
acts as supporting fiber on which balsam-pear-like poly(methyl methacrylate) knots are distributed for Rayleigh instability effect. Such spider-silk-like structures exhibit fog harvesting capacity. During the process of solvent evaporation, phase separation and selective removal of a certain phase from the mixed polymers, the bimodal and spinodal structures have been acquired. ${ }^{57}$

Thanks to the two great advances in ES, namely the coaxial $^{58,59}$ and side-by-side ES techniques, ${ }^{\mathbf{5 8 , 6 0}}$ not only the multi-level structures on the NF surface but also NFs with controllable inner multi-level structures have been fabricated successfully. Compared to other methods, it is attractive for the fabrication of a number of core-shell or anisotropic materials, since ES is a simple and efficient method. Notable examples include coaxial, microfluidic manifold, and triple-layer coaxial structures. ${ }^{61,62}$ For instance, Lahann and Bhaskar prepared multi-compartmental fibers via co-jetting ES using two or more poly(lactide-co-glycolide) polymers, which yielded biodegradable micro-fibers with multiple chemically distinct compartments. ${ }^{63}$ The individual compartments can be identified from their chemical compositions, which are controlled by the chemical composition of the initial jetting solutions. Confocal laser scanning microscopy study revealed the extremely wellshaped multi-fibers and the clear boundaries between those compartments in the fibers. ${ }^{63}$

Recently, two-dimensional (2D) nanowebs (Fig. 3f) have been generated by optimizing the processing parameters in ES technique. ${ }^{64}$ The electrospun micro-fibers act as a support for the network nanowebs with interlinked 1D NFs. The mean diameter of the NFs contained in the typical nanowebs is about one order of magnitude less than that of conventional electrospun fibers. Until now, various nanowebs have been successfully prepared using different polymer systems such as nylon$6,{ }^{64}$ polyacrylic acid (PAA) ${ }^{64,65}$ and PAA/nylon- $6 .{ }^{52}$ The formation, morphology, and density of the nanowebs in the electrospun fibrous membranes are strongly affected by applied voltage, relative humidity, used solvents, solution concentration, and distance between the capillary tip and the collector.

Three-dimensional (3D) fibrous macro-structures can be effectively fabricated by ES technique. The most direct way is to create the multilayered NF structures by the sequential ES technique. By this way, fibrous membrane with a certain thickness up to hundreds of microns can be obtained, although this strategy may take a long time (usually from $20 \mathrm{~min}$ to $20 \mathrm{~h}$ ) to achieve a sufficient 3D structure. Another way is postprocessing of the electrospun fibers, such as peeling off the electrospun thin film from the collector, and then bending or stacking the fiber layers into a 3D fibrous structure like pipe or thick mat. ${ }^{6,67} 3 \mathrm{D}$ NF structures can also be successfully obtained by replacing the conventional $2 \mathrm{D}$ flat collector by a 3D one. ${ }^{68,69}$

\subsection{Electrospun polymer NFs doped with CNTs}

It is well known that the filling of CNTs into the electrospun polymeric NFs can greatly influence the mechanical, electrical, and thermal properties of NFs, but it is not so easy to align CNTs along the axis of the created NFs. To maximize the reinforcement of CNTs in polymer composites, the alignment and dispersion of CNTs in NFs are two important factors should be considered. Recently, CNT-filled NF membranes have been produced using ES technique to improve electrical characteristics. $^{\mathbf{7 0}-77}$

In 2004, Reneker's group for the first time found that the orientation of MWCNTs within the electrospun NFs was much higher than that within the polyacrylonitrile (PAN) polymer crystal matrix (Fig. 4a) ${ }^{78}$ This finding suggests that not only the surface tension and jet elongation but also the slow relaxation of MWCNTs in NFs are the key factors for the orientation of MWCNTs. As a result of the highly anisotropic orientation of MWCNTS in the polymer NFs, the fabricated PAN-MWCNT nanofibrous mats possessed enhanced properties like electrical conductivity, mechanical strength, thermal stability, and dimensional stability. With natural polymer, Jin's group prepared silk fibroin fibers, ${ }^{79}$ where MWCNTs were embedded and well aligned (Fig. 4b). Meanwhile, Haddon's group studied SWCNT reinforced polymer composite membranes using ES technique. ${ }^{80}$ NFs with diameters in the range of 50-100 nm were obtained by spinning SWCNTs filled PS composites. TEM observations revealed that the incorporation of small bundles of SWCNTs orient parallel to the NF axis (Fig. 4c). By using a posttreatment process, Lee's group prepared the mesoporous CNTembedded carbon NFs (Fig. 4d). ${ }^{81}$

ES can also be used to fabricate NFs with multi-component polymer matrix. For instance, Mallon's group synthesized graft copolymers of polyacrylonitrile-graft-poly(dimethyl

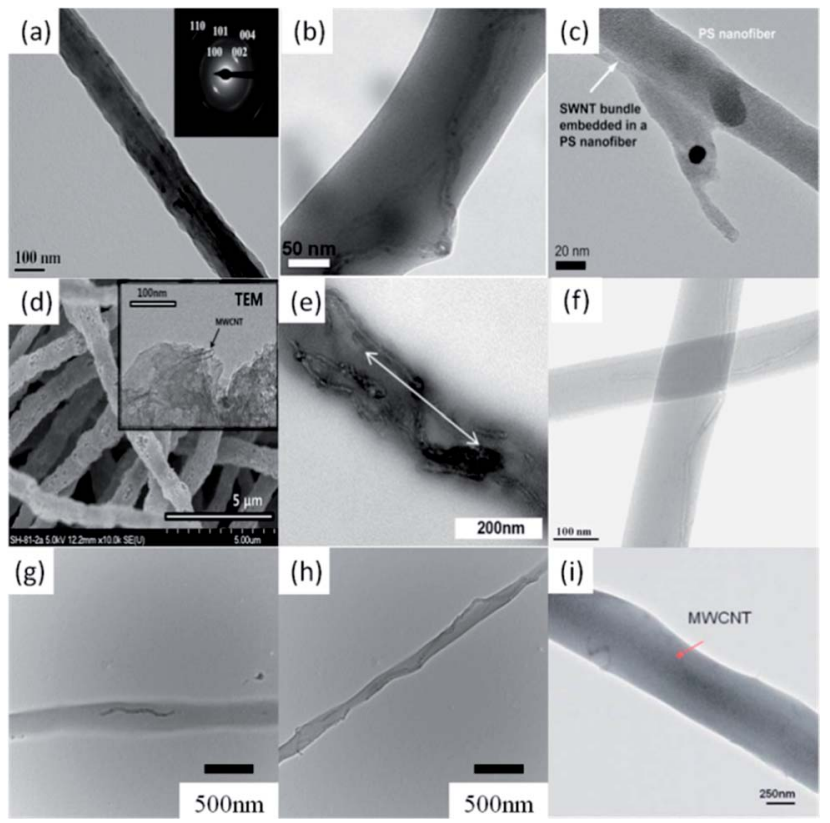

Fig. 4 Electrospun polymer NFs doped with CNTs: (a) PAN-MWNT, (b) silk fibroin-MWCNT, (c) SWNT bundle (white arrow) embedded in the PS NFs, (d) mesoporous carbon NF-MWCNT, (e) PAN-g-PDMSMWCNT, (f) PVP-MWCNT, (g) PEO-MWCNT hybrid NFs with $0.5 \%$ MWCNT, (h) PEO-MWCNT hybrid NFs with 3\% MWCNT, and (i) PUMWCNT. 
siloxane) (PAN-g-PDMS) by ES.$^{82}$ The amphiphilic property of the graft copolymers induced phase segregation and selfassembly of copolymers in solution to form a network-like structure. The self-assembly has a direct effect on the final formation and morphologies of NFs. MWCNTs were also introduced into the amphiphilic copolymer NFs by ES. The addition of MWCNTs produced fibers with much smaller diameters, but the porous structure on fibers was maintained (Fig. 4e). In the same year, Shim's group fabricated copolymer NFs doped with MWCNTS by ES and utilized the fabricated NFs as a chemiresistor to detect the aromatic volatile organic compounds (Fig. 4 f)..$^{83}$

Previously we reported that both the alignment of MWCNTs in the electrospun PEO NFs and the orientation of electrospun PEO-MWCNT hybrid NFs can be controlled by an advanced ES technique. ${ }^{6}$ The embedding and alignment of MWCNTs in PEO NFs were confirmed by TEM, as shown in Fig. $4 \mathrm{~g}$ and $\mathrm{h}$. With the increasing of content of MWCNTs in the electrospun NFs, MWCNTs were tended to align closely in a line, forming an ideal structure that can best express the unique anisotropic properties of CNTs. In a next study, we further investigated the preparation of polyurethane (PU) NFs filled with MWCNTs and created a novel PU-MWCNT conductive fibrous membrane with ES technique (Fig. 4i). ${ }^{8}$

The use of CNTs to reinforce and enhance the performance of polymer-CNT hybrid NFs can produce a new generation of composite materials. The above introduction highlights the fact that the intrinsic crystalline quality and the straightness of the embedded CNTs are significant factors influencing the reinforcement capability. Meanwhile, in the electrospun polymer-CNT composites, polymers not only act as the matrix for the uniform distributions of CNTs and the formation of a thin film, but also play a significant role in enhancing the electrochemical characteristics by means of their interactions with CNTs.

\subsection{Applications as sensors and biosensors}

Electrospun polymer-CNT NFs have wide applications for the fabrication of electrochemical sensors and biosensors.

2.3.1 Sensing of alcohols. Shim and co-workers firstly doped MWCNT-OH into nylon-6,6 and created the nylonMWCNT hybrid NFs by ES technique. ${ }^{84}$ They further investigated the sensing properties of the created nylon-MWCNT NFs by measuring their responses upon exposure to low molecularweight alcohol vapours, such as methanol, ethanol, 1-propanol, and 1-butanol (Fig. 5a). The changes of the electrical resistance of nylon-MWCNT hybrid NFs were demonstrated on the basis of hydrogen bonds among the alcohol vapours and hydroxyl groups (-OH) on MWCNT-OH, and amide groups (-NHCO-) in nylon-6,6. CNT is p-type semiconductor at room temperature. Therefore, electron donating groups (alcohols) will donate electrons into the valence band of CNT, resulting in chargecarrier $(\mathrm{h}+)$ recombination when exposed to alcohol vapours. The adsorbed alcohol vapours can also reduce the charge mobility of CNTs via providing scattering sites. As a result, the resistance of nylon-MWCNT hybrid NFs is increased during
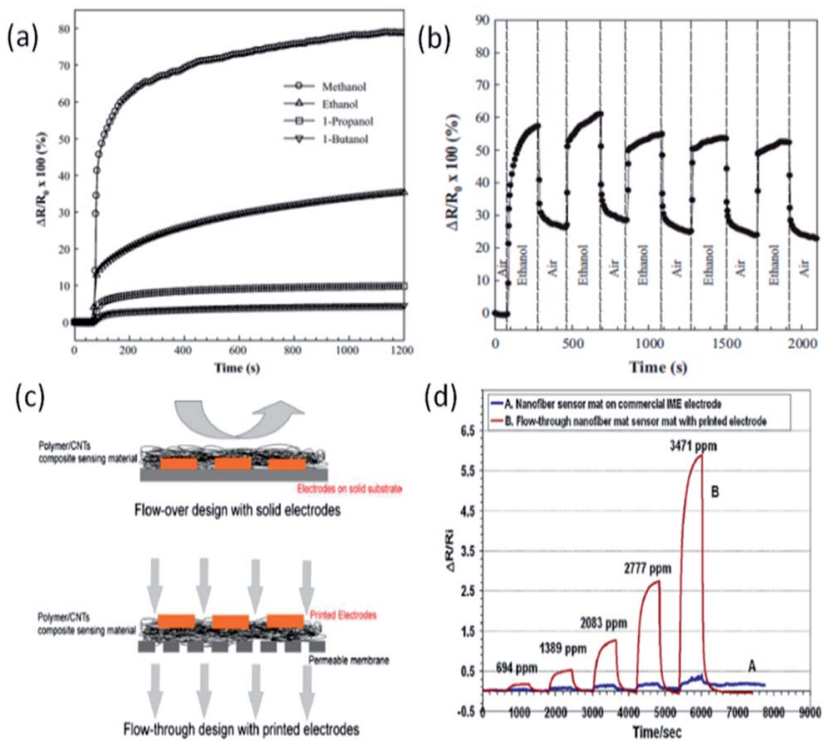

Fig. 5 (a) Electrical responses of electrospun nylon-MWCNT hybrid NFs to alcohol vapours, (b) cyclic electrochemical response to ethanol vapour; (c) schematic presentation that shows the comparison between a flow-over design (top) and a flow-through design (bottom); (d) comparison of the sensor response profile of a flow-through sensing mat with a printed electrode and a non-flow through sensing mat on commercial IME electrodes.

sensing of alcohol vapours. This kind of sensors fabricated by nylon-MWCNT hybrid NFs showed reversible and reproducible responses to ethanol vapours within five cyclic tests, as shown in Fig. $5 \mathrm{~b}$.

Recently, Han et al. developed an integrated sensor system by using electrospun poly(methyl methacrylate) (PMMA)SWCNT hybrid NFs combined with the inter-digitated electrodes directly printed on a surface to detect volatile organic compounds. ${ }^{85}$ When the polymer in the NFs swells due to the vapor adsorption, the CNTs separate from each other and increase the electrical resistance of this kind of material. The conductivity change of the hybrid NF material was recorded when the material was exposed to volatile organic compounds. The response to different vapors showed a linear relationship between resistance change and vapor concentration. In their study, polymer-CNT NFs were electrospun onto a porous gaspermeable membrane. The design of this integrated sensor system (porous membrane backing, NF mat with printed electrodes) enables the flow-through design, as shown in Fig. 5c. The high permittivity of this integrated NF sensor system allows gas to interact with the sensing material in 3D, thus resulting in enhanced sensitivity for sensing. They have obtained a oneorder-of-magnitude sensitivity enhancement with the permeable sensor when compared to the electrodes modified by directly depositing NFs (Fig. 5d).

2.3.2 Sensing of glucose and $\mathrm{H}_{2} \mathrm{O}_{2}$. Electrochemical biosensors utilizing enzyme-modified electrodes have received considerable attention, due to their high sensitivity and specificity. To implement the full potential of enzymatic electrochemical biosensors, the host material (substrate) should have 
high-surface area, optimum porosity, high thermal stability, chemical inertness, and negligible swelling in aqueous and non-aqueous solutions. ${ }^{86}$ Electrospun fibrous membrane meets many of the requirements to achieve improved performances as a sensor material. The main benefits of electrospun NFs to the fabrication of sensors include design flexibility, dimensional stability for gas and liquids, high surface area, safe operations, easy scaling, and high reusability.

Lee et al. constructed CNT-doped PAN porous NFs by ES technique and further modified the NFs with glucose oxidase (GOD) for electrochemical sensing of glucose. ${ }^{27}$ The specific surface area and pore volume of the thermal-treated electrospun carbon fibers (CNFs) can be increased by immobilizing GOD. CNTs were embedded as an electrically conductive additive to improve the electrical property of the porous CNFs. The effects of CNT addition and oxyfluorination on the performance of the fabricated glucose sensor were investigated with cyclic voltammogram (CV). The current peak intensity in the CVs increased due to the effects of CNT additive and oxyfluorination treatment. This result is attributed to efficient GOD immobilization and the improved affinity between GOD and the surface resulting from the introduced hydrophilic functional groups on carbon surface and the efficient electron transfer. When glucose was freshly injected to achieve higher glucose concentrations, the stabilization time of the current was approximately $7 \mathrm{~s}$ at every step. This rapid stabilization of current is attributed to the enhanced effect of CNTs on the electrical properties of electrode.

In the next study, Lee and co-workers fabricated another glucose sensors by immobilizing GOD onto electrospun polymer (poly(diallyldimethylammonium chloride) (PDDA) and PMMA)-MWCNT nanofibrous membranes. ${ }^{28}$ The fabricated PMMA(PDDA)-MWCNT/GOD exhibits excellent electrocatalytic activity towards hydrogen peroxide $\left(\mathrm{H}_{2} \mathrm{O}_{2}\right)$ with a pronounced oxidation current at $+100 \mathrm{mV}$. Glucose was amperometrically detected at $+100 \mathrm{mV}$ in $0.1 \mathrm{M}$ phosphate buffer solution (PBS, $\mathrm{pH} 7)$. The linear response for glucose detection is in the range of $20 \mu \mathrm{M}$ to $15 \mathrm{mM}$ with a detection limit of $1 \mu \mathrm{M}$ and a response time of $\sim 4 \mathrm{~s}$. The superior performance of this kind of sensors is due to the wrapping of PDDA over MWCNTs that bound with GOD.

\section{Electrospun polymer NFs doped with MNPs for electrochemical sensing}

\subsection{Electrospun polymer NFs doped with MNPs}

It is well-known that the electrochemical activity of MNPs is extremely sensitive to their sizes, sharp, and dispersion. A high dispersion of MNPs in functional materials is important to present high electrochemical activity, while the associated tendency of MNPs to aggregate would lower their catalytic activity and reuse life-time. Therefore, how to design and prepare MNP-based materials with long-term dispersion stability and high catalytic efficiency is a primary challenge for their widely applications. Several strategies have been utilized to synthesize and immobilize MNPs into electrospun polymer
NFs. ${ }^{87-90}$ For instance, polymer-MNP hybrid NFs can be prepared by mixing MNPs into a polymer solution and spinning subsequently. ${ }^{87}$ MNPs can also be directly deposited onto electrospun polymer NFs via surface modication. ${ }^{8 \mathbf{8 1} 9 \mathbf{9 3}}$ Alternatively, MNPs can be synthesized on the surface of electrospun polymer NFs through thermal and chemical reduction of metallic precursor ions. ${ }^{\mathbf{8 9}, 90}$

Du et al. prepared the highly uniform and monodisperse noble MNPs (Ag, Au, and Pt) in polyvinyl alcohol (PVA) NFs by combining ES technique and an in situ reduction. ${ }^{94}$ The small and stable MNPs can be easily synthesized in aqueous solution using epigallocatechin gallate as both reductant and stabilizer. Through ES technique, uniform and smooth PVA NFs decorated with uniform and highly dispersed MNPs can be obtained (Fig. 6a). Zhang et al. prepared PAN NFs decorated with AgNPs by ES technique. AgNPs were created on the PAN NFs with a seed-mediated electroless plating. ${ }^{95}$ A typical TEM image is shown in Fig. 6b, in which numerous AgNPs were attached onto an PAN NFs. The AgNPs were roughly spherical in shape and were randomly distributed on the surface of the NFs with a moderate density. The size distribution of AgNPs is $23.3 \pm 5.3$ $\mathrm{nm}$. Lei and co-workers reported the successful preparation of polyaniline (PANi) NFs with integrated Pt nanoflowers. ${ }^{96}$ PANi was prepared by in situ polymerization of aniline on an electrospun NF template in an acidic solution with ammonium persulfate as the oxidant. Pt nanoflowers were further electrodeposited onto the PANi NF backbone by CV, resulting in novel functionalized hybrid NFs. The coverage of Pt nanoflowers on PANi NFs can be facilely controlled by adjusting the electrodeposition parameters (Fig. 6c).

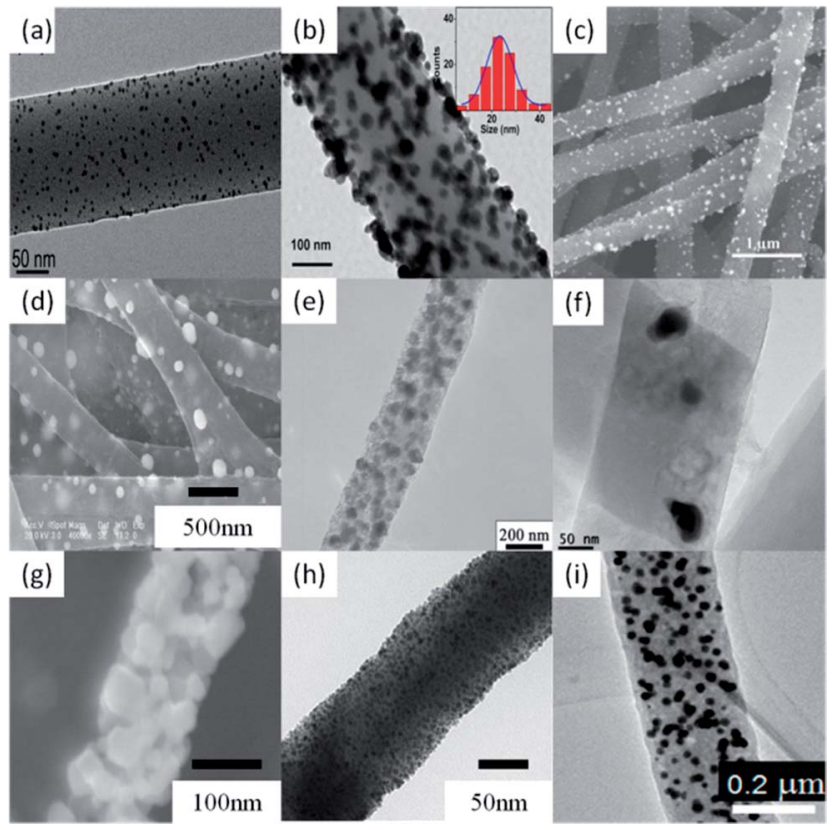

Fig. 6 Electrospun polymer NFs doped with different MNPs: (a) PVAAuNP; (b) PAN-AgNP; (c) PANi-PtNP; (d) CNF-PdNP; (e) CF-NiNP; (f) CNR-CoNP; (g) ZnO-CuNP; (h) Rh-doped $\mathrm{ZrO}_{2}$ NFs; (i) CNF$\mathrm{Pd}_{30} \mathrm{Ni}_{70}$. 
You's group prepared PdNP-modified CNFs by ES and subsequent thermal treatments. ${ }^{97}$ Fig. $6 \mathrm{~d}$ shows the SEM image of the electrospun CNF-PdNP hybrid. The surface of CNFs is coarse and the diameter is in the range of 200$500 \mathrm{~nm}$. The spherical PdNPs with a mean diameter of about $75 \mathrm{~nm}$ can be observed on the surface of CNFs. Meanwhile, they also prepared NiNP-loaded CNFs (CNF-NiNP) by combination of ES technique and thermal treatment. ${ }^{98}$ The TEM image illustrates that the NiNPs with a diameter of about $50 \mathrm{~nm}$ are embedded in the CNF matrix (Fig. 6e). Shanmugam et al. fabricated CoNP-doped porous carbon nanorods (CNR-CoNP) by an easy and versatile ES technique and followed by one-step carbonization at $900{ }^{\circ} \mathrm{C}$ in $\mathrm{Ar} .{ }^{99}$ FE-TEM analysis clearly shows that the CoNPs are actually embedded in the CNRs (Fig. 6f). The size of CoNPs ranges from $20 \mathrm{~nm}$ to $100 \mathrm{~nm}$. Wang's group synthesized $\mathrm{Cu}$-doped ZnO NFs via ES technique. ${ }^{100}$ The SEM image of the assynthesized Cu-doped ZnO NFs is shown in Fig. 6g.

Xia's group reported a simple method for functionalizing the surface of $\mathrm{ZrO}_{2}$ nanofibrous membranes with RhNPs. ${ }^{101}$ The $\mathrm{ZrO}_{2}$ membranes were fabricated in the form of nonwoven mats by ES with a solution of polyvinylpyrrolidone (PVP) and zirconium acetylacetonate, followed by calcination in air at $550{ }^{\circ} \mathrm{C}$ to yield the tetragonal phase. The fibrous mats were then immersed in a polyol reduction bath to coat the surface of the NFs with RhNPs of $2-5 \mathrm{~nm}$ in size. Guo et al. successfully prepared Pd-Ni alloy NPs on CNFs (CNF-PdNi) by a simple method involving ES of precursor PAN $/ \mathrm{Pd}(\mathrm{acac})_{2} / \mathrm{Ni}(\mathrm{acac})_{2} \mathrm{NFs}$, followed by a thermal process to reduce metals and carbonize PAN (Fig. 6i).$^{102}$ The size, composition, and alloy homogeneity of the Pd-Ni alloy NPs could be readily tailored by controlling the feed ratio of metal precursors and the thermal treatment process.

\subsection{Applications as sensors and biosensors}

ES technique can be used to prepare MNP-CNF composites for electrochemical sensing applications by spinning metal precursor-containing polymer NFs, followed by a thermal treatment. ${ }^{103,104}$ The advantages of this method include the uniform dispersion of MNPs within the framework of CNF, the high electrical conductivity of CNF, and the highly porous and mechanically strong network structure of the resulting composite, which contribute to a high electrochemical activity by providing a larger active surface area, preventing MNPs from detachment and agglomeration, and facilitating electron and mass transfer within the system.

3.2.1 Sensing of $\mathrm{H}_{2} \mathrm{~S}$ and $\mathrm{H}_{2}$ gas. Wang and co-workers synthesized Cu-doped $\mathrm{ZnO}$ NFs via ES technique. ${ }^{100}$ The effects of $\mathrm{Cu}$ doping on $\mathrm{H}_{2} \mathrm{~S}$ sensing properties at low concentration $(1-10 \mathrm{ppm})$ were investigated at $230^{\circ} \mathrm{C}$. The results show that the $\mathrm{H}_{2} \mathrm{~S}$ sensing properties of ZnO NFs are effectively improved by $\mathrm{Cu}$ doping: $6 \mathrm{wt} \% \mathrm{Cu}$-doped $\mathrm{ZnO}$ NFs show a maximum sensitivity to $\mathrm{H}_{2} \mathrm{~S}$ gas, and the response to $10 \mathrm{ppm}$ $\mathrm{H}_{2} \mathrm{~S}$ is one order of magnitude higher than that of pure $\mathrm{ZnO}$ NFs. Fig. 7a shows the response of $\mathrm{Cu}$-doped $\mathrm{ZnO}$ gas sensors exposed to different concentrations of $\mathrm{H}_{2} \mathrm{~S}$. It is observed that
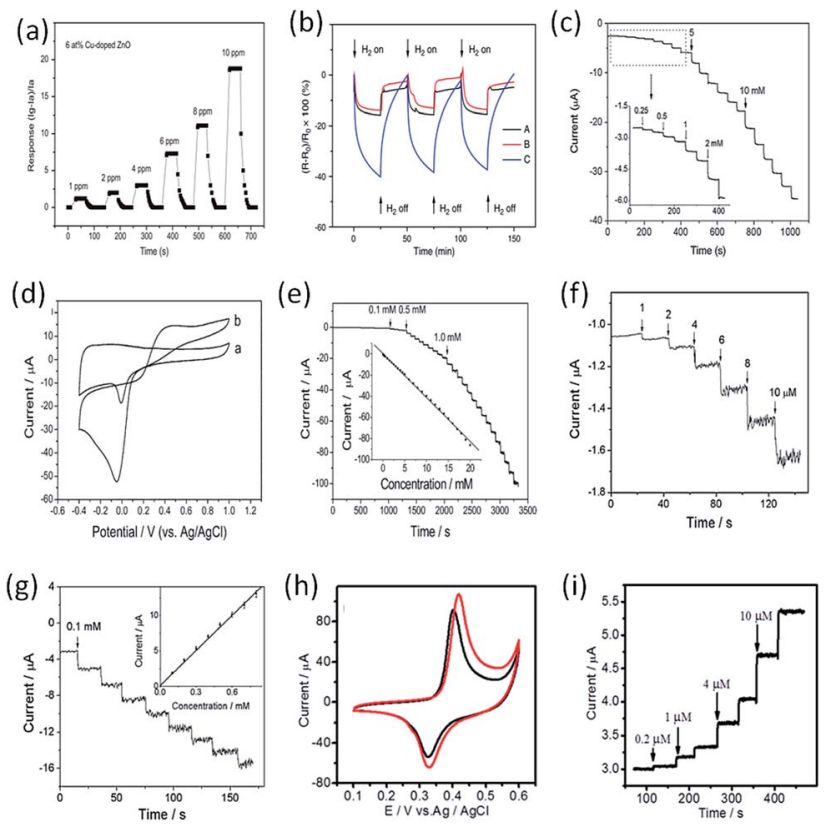

Fig. 7 Electrochemical sensing: (a) Cu-doped ZnO NFs sensor for sensing of $\mathrm{H}_{2} \mathrm{~S}$, (b) CNF-PdNP for sensing of $\mathrm{H}_{2}$, (c) CFP-NiNP based sensor for ethanol, (d and e) CNF-PdNP based sensor for $\mathrm{H}_{2} \mathrm{O}_{2}$ and glucose, (f, g) CNF-PtNP based sensor for $\mathrm{H}_{2} \mathrm{O}_{2}$, (h and i) CNF-PdNi based sensor for sugars.

the response of the sample increases with the increasing of $\mathrm{H}_{2} \mathrm{~S}$ gas concentration. The response time and the recovery time are 18 and $20 \mathrm{~s}$, respectively.

Fong et al. prepared carbon nanofibrous mat (nano-felt) surface-attached with PdNPs by ES, and explored its application for hydrogen $\left(\mathrm{H}_{2}\right)$ sensing. ${ }^{105} \mathrm{Fig}$. $7 \mathrm{~b}$ shows the variations of sensor responses when the device was exposed to $\mathrm{H}_{2}$ and vacuum alternatively. The results indicated that the resistance of carbon nano-felts decreased quickly upon exposure to $\mathrm{H}_{2}$ in the testing chamber, but the rate of resistance change was reduced upon prolonged exposure time; the resistance essentially returned to the original value after $\mathrm{H}_{2}$ flow was turned off, indicating that the sensor response was reversible. It was evident that the carbon nano-felt with PdNPs had substantially higher sensitivity on $\mathrm{H}_{2}$ due to the electronic interactions among $\mathrm{H}_{2}$ molecules, PdNPs, and carbon nano-felt, and the adsorbed $\mathrm{H}_{2}$ molecules would react with PdNPs to form palladium hydride when the nano-felt was exposed to $\mathrm{H}_{2}$.

3.2.2 Sensing of ethanol. You's group developed a novel NiNP-loaded carbon fiber paste (CFP-NiNP) electrode for enzyme-free determination of ethanol. ${ }^{104}$ An ES technique was used to prepare the CFP-NiNP composite with large amounts of spherical nanoparticles firmly embedded in CFP. In application to electroanalysis of ethanol, the CFP-NiNP-modified electrode exhibited high amperometric response and good operational stability. The calibration curve was linear up to $87.5 \mathrm{mM}$ with a detection limit of $0.25 \mathrm{mM}$, which is superior to that obtained with other transition metal based electrodes (Fig. 7c).

3.2.3 Sensing of $\mathrm{H}_{2} \mathrm{O}_{2}$ and sugars. Hou and co-workers synthesized PdNP-loaded CNFs (CNF-PdNP) by the 
combination of ES and thermal treatment processes. ${ }^{106}$ The CNF-PdNP-modified carbon paste electrode (CNF-PdNP/CPE) demonstrated direct and mediatorless responses to $\mathrm{H}_{2} \mathrm{O}_{2}$ at low potentials. Fig. $7 d$ shows the CVs of CNF-PdNP/CPE in 0.1 M PBS (pH 7.0) (curve a) and PBS containing $5 \mathrm{mM} \mathrm{H}_{2} \mathrm{O}_{2}$ (curve b) recorded at $50 \mathrm{mV} \mathrm{s}^{-1}$. When no $\mathrm{H}_{2} \mathrm{O}_{2}$ was added, the peak appeared at $-7 \mathrm{mV}$ was the reduction peak of the oxide of Pd. The $\mathrm{H}_{2} \mathrm{O}_{2}$ reduction peak potential at the CNF-PdNP/CPE is at $-48 \mathrm{mV}$, which is much lower than that at AgNP-modified glassy carbon electrode (GCE) $(-0.68 \mathrm{~V}$ vs. SCE), This result suggested a faster electron transfer rate and higher electrocatalytic activity toward the reduction of $\mathrm{H}_{2} \mathrm{O}_{2}$ at the CNF-PdNP/ CPE. Fig.7e shows the typical current-time plot of the CNF$\mathrm{PdNP} / \mathrm{CPE}$ at $-0.2 \mathrm{~V}$ with the successive addition of $\mathrm{H}_{2} \mathrm{O}_{2}$. After $\mathrm{H}_{2} \mathrm{O}_{2}$ was added into the stirring buffer solution, the sensor responded rapidly to reach a steady state. The sensor could achieve $95 \%$ of the steady-state current within $5 \mathrm{~s}$. The CNF$\mathrm{PdNP} / \mathrm{CPE}$ displayed a wider linear range from $0.2 \mu \mathrm{M}$ to $20 \mathrm{mM}$ with a correlation coefficient of 0.9991 and a slope of 4.15 $\mu \mathrm{A} \mathrm{mM}{ }^{-1}$ (inset, Fig. 7e).

Liu et al. produced a novel PtNP-loaded carbon NF (CNFPtNP) electrode with ES technique, and further applied the electrode for sensing of $\mathrm{H}_{2} \mathrm{O}_{2}{ }^{107}$ When applied to the electrochemical detection of $\mathrm{H}_{2} \mathrm{O}_{2}$, the CNF-PtNP electrode exhibited low over-potential, fast response, and high sensitivity. In addition, the CNF-PtNP electrode showed good selectivity for $\mathrm{H}_{2} \mathrm{O}_{2}$ detection in the presence of ascorbic acid, acetaminophenol and uric acid under physiological $\mathrm{pH}$ condition. Fig. $7 \mathrm{f}$ shows the amperometric responses of the CNF-PtNP electrode upon successive addition of $\mathrm{H}_{2} \mathrm{O}_{2}$ at different concentrations. The electrode exhibited strong and fast response to each injection of analyte, attributing to the high electrocatalytic efficiency of the well-dispersed PtNPs. Fig. $7 \mathrm{~g}$ indicates the amperometric responses of the CNF-PtNP electrode when injecting $0.1 \mathrm{mM}$ $\mathrm{H}_{2} \mathrm{O}_{2}$ for eight times. With this electrospun electrode, a detection limit of $0.6 \mu \mathrm{M}$ with a linear range of $1-800 \mu \mathrm{M}(R=0.9991)$ was obtained.

Guo et al. successfully prepared Pd-Ni alloy NP-doped carbon NFs (CNF-PdNi) composites by a simple method involving ES of precursor PAN/Pd(acac $)_{2} / \mathrm{Ni}(\mathrm{acac})_{2} \mathrm{NFs}$, followed by a thermal process to reduce metals and carbonize PAN. ${ }^{102} \mathrm{CV}$ studies showed that the CNF-PdNi-based electrodes reveal enhanced redox properties compared to the Ni-metal electrode and show significantly improved electrocatalytic activity to sugars (e.g., glucose, fructose, sucrose, and maltose) oxidation (Fig. 7h and i). The application potential of CNF-PdNi-based electrodes in flow systems for sugar detection was explored. A very low limit of detection for sugar (e.g., 7-20 nM), high resistance to surface fouling, excellent signal stability and reproducibility, and a very wide detection linear range (e.g., 0.03-800 $\mu \mathrm{M}$ ) were revealed for this new type of CNF-PdNi composite as the detecting electrode.

Devadoss's group reported the electrochemical application of AuNP-decorated Nafion NFs (NNF-AuNP) using a facile ES technique. ${ }^{108}$ Owing to the uniform distribution and large surface area of the AuNPs in the NNFs, the NNF-AuNP-modified electrodes gave rise to greatly improved electrochemical properties compared to AuNP-free electrodes. When they were employed as reservoirs for immobilizing horseradish peroxidase (HRP), reliable and sensitive electrochemical detection by the enzyme reaction was achieved. The detection sensitivity for $\mathrm{H}_{2} \mathrm{O}_{2}$ was determined to be as low as $38 \mathrm{nM}$. In addition, there was no change in the enzyme stability over three weeks. To determine the electrochemical response to $\mathrm{H}_{2} \mathrm{O}_{2}, \mathrm{CV}$ was performed in the absence and presence of $0.01 \mathrm{mM} \mathrm{H}_{2} \mathrm{O}_{2}$ (Fig. 8a), where HRP-immobilized NNFs and NNF-AuNP-modified electrodes were compared. Upon the addition of $0.01 \mathrm{mM} \mathrm{H}_{2} \mathrm{O}_{2}$, the most noticeable change in the current was observed for the NNF-AuNP electrode. The current density of NNF-AuNP/HRPmodified electrodes was almost 2.4-fold greater than that of NNF/HRP-modified electrodes. This result clearly indicates that the AuNPs play a critical role in $\mathrm{H}_{2} \mathrm{O}_{2}$ reduction through catalyzing HRP enzyme on the composite electrode. Furthermore, the NNF-AuNP-modified electrode in the absence of HRP did not show the distinct redox peak even at high concentrations of $\mathrm{H}_{2} \mathrm{O}_{2}$ indicating that the reduction of $\mathrm{H}_{2} \mathrm{O}_{2}$ at the electrode surface is predominantly catalyzed by the immobilized HRP. This kind of $\mathrm{H}_{2} \mathrm{O}_{2}$ sensor has a good linear range from as $6 \times$ $10^{-8}$ to $8 \times 10^{-7} \mathrm{M}$ (inset in Fig. 8b) with a current sensitivity of $0.3242 \mu \mathrm{A} \mu \mathrm{M}^{-1}$.

Yu's group reported a facile route to fabricate water stable AuNP-poly(vinyl alcohol) (PVA-AuNP) hybrid nanofibrous mats with tunable densities of AuNPs and further demonstrated the (a)

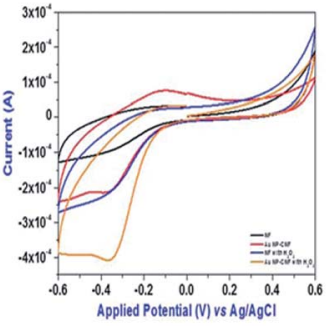

(c)

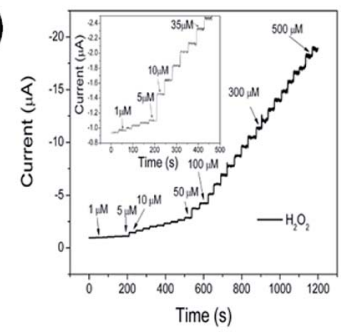

(b)

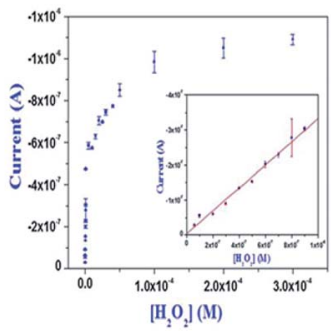

(d)

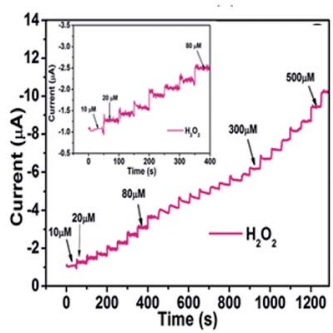

(e)

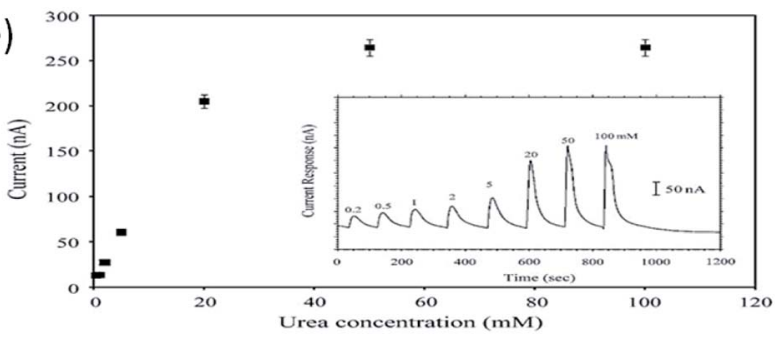

Fig. 8 Electrochemical biosensors: (a and b) NNF-AuNP and HRP based biosensor for $\mathrm{H}_{2} \mathrm{O}_{2}$, (c) PVA-AuNP and HRP based biosensor for $\mathrm{H}_{2} \mathrm{O}_{2}$, (d) PVA-AgNP and HRP based biosensor for $\mathrm{H}_{2} \mathrm{O}_{2}$, and (e) PANi-Pt based biosensor for urea. 
potential application of as-prepared PVA-AuNP nanofibrous mats as efficient $\mathrm{H}_{2} \mathrm{O}_{2}$ biosensor substrate materials. ${ }^{109}$ In the electrospinning process, the uniformity of electrospun PVA nanofibers is greatly influenced by the properties of polymer solution and the operating parameters. In their study, PVA solution ( $8 \mathrm{wt} \%$ ) was prepared by dissolving PVA powder into deionized water at $95{ }^{\circ} \mathrm{C}$ overnight under magnetic stirring, and then the solution was cooled down to room temperature naturally. Subsequently, the glutaraldehyde solution was added to PVA aqueous solution under vigorous stirring to achieve a homogeneous viscoelastic spinnable solution, in which the mass ratio of PVA and GA was $4: 1$. The optimized experimental parameters including flow rate of $0.3 \mathrm{~mL} \mathrm{~h}^{-1}$, voltage of $9 \mathrm{kV}$, and collection distance of $17 \mathrm{~cm}$. Fig.8c shows the amperometric response and calibration curve of steady state current $v s$. concentration of $\mathrm{H}_{2} \mathrm{O}_{2}$. Stepped increases of the amperometric reduction currents were observed with the addition of $\mathrm{H}_{2} \mathrm{O}_{2}$ at a constant potential of $-0.2 \mathrm{~V}$. The current response of the sensors was rapidly enhanced and approached about $98 \%$ of its steady state current within $1 \mathrm{~s}$. The obvious increase of the reduction current can be observed when the concentration of $\mathrm{H}_{2} \mathrm{O}_{2}$ was as low as $1 \mu \mathrm{M}$ (inset picture in Fig. 8c) for PVA-AuNP/ HRP-modified GCE. The amperometry result indicates that the PVA-AuNP/HRP-modified GCE exhibits very high sensitivity.

Du et al. prepared highly uniform and mono-disperse noble MNPs (Ag, Au, Pt) in PVA NFs by combining the in situ reduction and ES technique, which can be used as efficient biosensor for the detection of $\mathrm{H}_{2} \mathrm{O}_{2} \cdot{ }^{94}$ In their research, $5 \mathrm{~g}$ PVA powder was dissolved in $45 \mathrm{~mL}$ deionized water to get a concentration of $10 \mathrm{wt} \%$ solution and was stirred at $80{ }^{\circ} \mathrm{C}$ for $5 \mathrm{~h}$ to obtain a transparent homogeneous solution. The solution was then cooled to room temperature and $10 \mathrm{~mL} 10 \mathrm{wt} \%$ PVA solution were injected into three 3-neck flask, respectively. The calculated amounts of $\mathrm{AgNO}_{3}(0.0375 \mathrm{~g}), \mathrm{HAuCl}_{4} \cdot 3 \mathrm{H}_{2} \mathrm{O}(0.0462 \mathrm{~g})$ and $\mathrm{H}_{2} \mathrm{PtCl}_{6} \cdot 6 \mathrm{H}_{2} \mathrm{O}(0.0642 \mathrm{~g})$ were added into the flasks, respectively. $0.025 \mathrm{~g}$ epigallocatechin gallate dissolved in $2 \mathrm{~mL}$ deionized water was injected into the above solutions, respectively. The solutions were kept at $65{ }^{\circ} \mathrm{C}$ under vigorously stirring for $3 \mathrm{~h}$ to ensure the complete reduction. After that, the precursor solutions for electrospinning were refrigerated at $4{ }^{\circ} \mathrm{C}$. The optimized experimental parameters including flow rate of $0.01 \mathrm{~mL} \mathrm{~min}^{-1}$, voltage of $12 \mathrm{kV}$, and collection distance of $12 \mathrm{~cm}$. The fabricated PVA-AgNP functionalized electrodes exhibit remarkably increased electrochemical catalysis toward $\mathrm{H}_{2} \mathrm{O}_{2}$ and excellent stability and reusability. The biosensor allows the highly sensitive detection of $\mathrm{H}_{2} \mathrm{O}_{2}$ with a broad linear range span of the concentration of $\mathrm{H}_{2} \mathrm{O}_{2}$ from $10 \mu \mathrm{M}$ to $560 \mu \mathrm{M}$ (Fig. 8d). The PVA-AgNP-based biosensor responded rapidly and approached about $98 \%$ of its steady state current less than 2 s. The rapid electrode response to the change of the $\mathrm{H}_{2} \mathrm{O}_{2}$ concentration is attributed to the fast diffusion of the $\mathrm{H}_{2} \mathrm{O}_{2}$ onto the surface of small AgNPs through the porous NF structures.

3.2.4 Sensing of urea. Lei's group prepared PANi NFs with integrated $\mathrm{Pt}$ nanoflowers (PANi-Pt). ${ }^{96}$ As a demonstration, urease is immobilized onto the PANi-Pt hybrid NFs and the composite was employed as the sensing platform for urea detection in a flow-injection-analysis (FIA) system. The detection of urea shows a wide linear range and an excellent anti-interference property against chloride ion. In addition, it was found that the response to urea was attributed not only to the conductivity change of PANi due to the interaction between PANi and ammonia (liberated from the enzymatic reaction), but also to the interaction between $\mathrm{Pt}$ nanoflowers and amine groups in urea. The inset of Fig. 8e exhibits the typical FIA amperometric response of the PANi-Pt/GCE to successive injection of urea operated at the optimal applied potential of $-0.1 \mathrm{~V}$. The developed urea biosensor displays a linear range up to $20 \mathrm{mM}$ with a correlation coefficient of 0.9968 , a sensitivity of $115.6 \mathrm{nA} \mathrm{mM}{ }^{-1} \mathrm{~cm}^{-2}$, and a detection limit of $10 \mu \mathrm{M}(S / N=3)$.

\section{Electrospun polymer NFs doped with CNTs and MNPs for electrochemical sensing}

\subsection{Electrospun polymer NFs doped with CNTs and MNPs}

The research of electrospun polymer NFs doped with CNTs and MNPs has been reported recently. ${ }^{\mathbf{1 1 0 , 1 1 1}}$ For example, Shi's group reported a new approach to immobilizing zero-valent iron

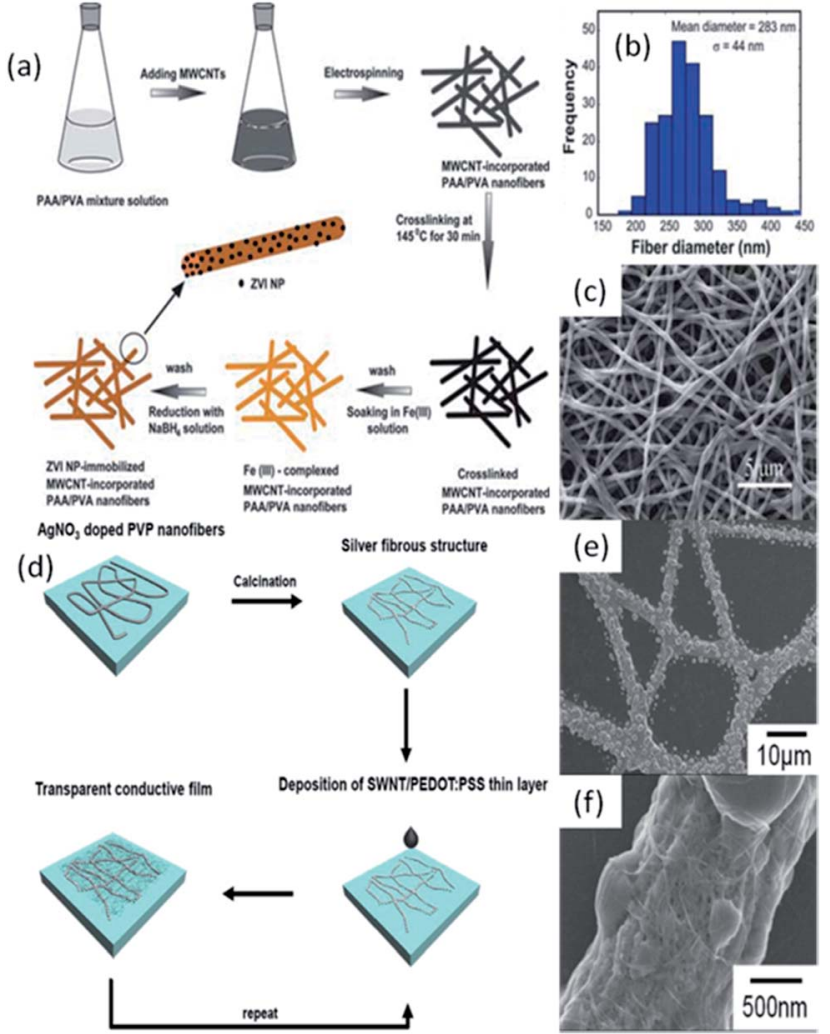

Fig. 9 (a) Schematic illustration of immobilizing ZVI NPs into MWCNTincorporated PAA/PVA NFs; (b) diameter distribution histogram of the same NFs after ZVI NPs immobilization; (c) SEM image of MWCNTincorporated PAA/PVA NFs after ZVI NPs immobilization; (d) schematic representation of the fabrication of a transparent conductive film using a silver fibrous microstructure and a SWNT/PEDOT:PSS film; (e and f) SEM images for silver fibrous microstructures with 10 layers of SWNT/ PEDOT:PSS at low and high magnifications, respectively. 
nanoparticles (ZVI NPs) into electrospun polymer NFs (Fig.9a). ${ }^{110}$ In their study, MWCNT incorporated PAA/PVA composite NFs were produced by spinning the PAA and PVA mixed solution containing well dispersed MWCNTs, and the thermal treatment was introduced to crosslink the NFs in order to obtain water-stable composite nanofibrous mats. Then, the water-stable composite nanofibrous mats were immersed into $\mathrm{FeCl}_{3}$ solution to complex $\mathrm{Fe}^{3+}$ for subsequent reductive formation and immobilization of ZVI NPs into the composite NF mats. A typical SEM micrograph of the ZVI NP-immobilized nanofibrous mats with MWCNTs (Fig. 9c) shows that the hybrid nanofibrous mat attains a porous structure with a smooth surface. The diameter of the ZVINP-immobilized NFs is narrowly distributed with a mean diameter of $283 \pm 44 \mathrm{~nm}$ (Fig. 9b).

Lee's group fabricated a SWNT/silver fiber-based transparent conductive film using silver fibers produced by the ES method and post-processing (Fig.9d). ${ }^{111}$ In their research, electrospun silver fibers provided a segregated structure with AgNPs within the fibrous microstructures. The individual AgNPs within the electrospun fibers on the substrate were interconnected with SWNTs, which resulted in the efficient activation of a conductive network by bridging the gaps among the separated AgNPs (Fig.9e and f).

Our group also made contributions to the fabrication of polymer NFs doped with CNTs and MNPs. ${ }^{8,9}$ For example, we reported the electrospun preparation of PU NFs filled with MWCNTs and AgNPs (PU-MWCNT-AgNP). ${ }^{8}$ By simply blending the suspension of modified MWCNTs and commercialized

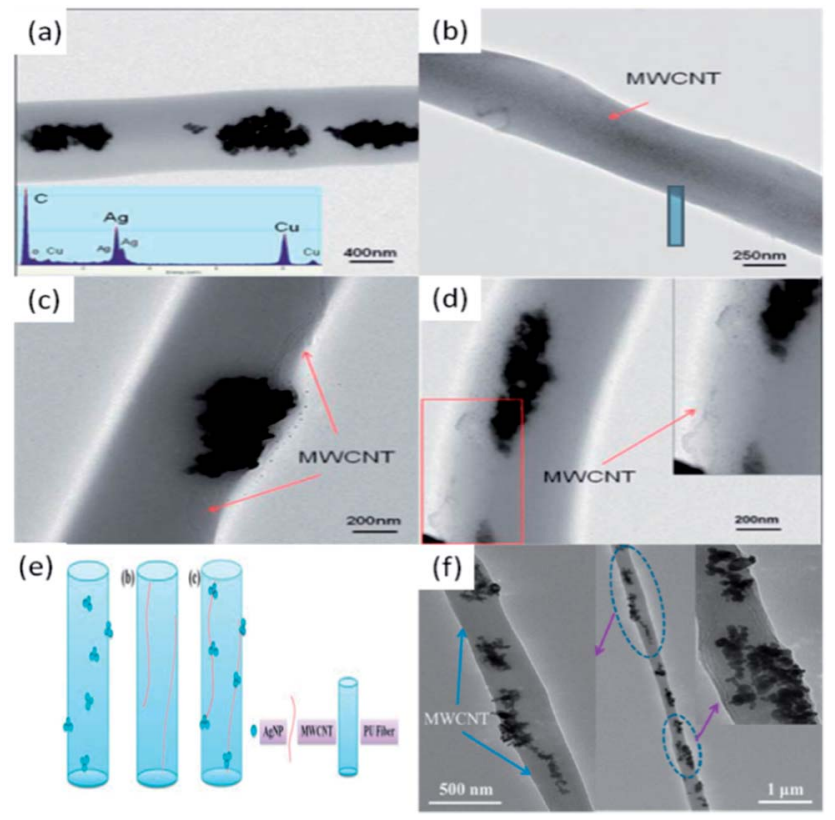

Fig. 10 (a) TEM image of PU-AgNP. The inset in (a) is the EDX spectrum of PU-AgNP NFs; (b) TEM image of PU-MWCNT; (c) and (d) TEM images of PU-MWCNT-AgNP hybrid NFs; (e) a proposed model for the dispersion of AgNPs or/and MWCNTs in (a) PU-AgNP, (b) PUMWCNT and (c) PU-MWCNT-AgNP NFs, respectively and (f) TEM images of PVDF-MWCNT-PtNP NFs.
AgNPs with PU solution and then performing ES, PU-MWCNTAgNP hybrid NFs were successfully prepared (Fig. 10a). It can be clearly seen that Ag clusters spread throughout the PU matrix discretely, without being connected to each other. With this ES technique, both PU-MWCNT and PU-MWCNT-AgNP NFs were fabricated successfully, and MWCNTs were successfully aligned and oriented in the PU matrix (Fig. 10b and c). It should be noted that in the PU-MWCNT-AgNP NFs, the Ag clusters tend to adhere to the surface of MWCNTs (Fig. 10c), and MWCNTs always act as bridges to combine the discrete $\mathrm{Ag}$ clusters together (Fig.10d). The assembly of MWCNTs and AgNPs can effectively facilitate the electron transfer, thus boosting the conductivity and improving the electrocatalytic performance of the materials. Based on the experimental data, we further proposed a potential model to display the distribution of MWCNTs and AgNPs inside the fabricated PU-MWCNT-AgNP NFs (Fig. 10e). The aligned MWCNTs act as bridges and get the discrete $\mathrm{Ag}$ clusters in series, which results in a notable synergistic effect and endows the PU-MWCNT-AgNP NFs with good conductivity and great potential in the application of electrochemical sensors.

Recently, we reported a novel $\beta$-phase polyvinylidene difluoride (PVDF) nanofibrous membrane decorated with MWCNTs and PtNPs. ${ }^{9}$ It is interesting to find that the PtNPs tend to attach onto the side walls of MWCNTs, and at the same time MWCNTs serve as bridges to connect the dispersive PtNPs together in PVDF-MWCNT-PtNP hybrid NFs (Fig.10f and its insets). The assembly of MWCNTs and PtNPs can effectively facilitate the electron transfer, thus boosting the conductivity and improving the electrocatalytic performance of the fabricated materials.

\subsection{Electrochemical sensing}

We are the first to apply electrospun polymer NFs (PVDF and PU) doped with MNPs and MWCNTs for electrochemical sensors of $\mathrm{H}_{2} \mathrm{O}_{2}$ and glucose. ${ }^{8,9}$ Considering the good electrocatalytic performance of AgNPs and the excellent conductivity of MWCNTs, the prepared PU-MWCNT-AgNP hybrid NFs are expected to have better performance than either PU-MWCNT or PU-AgNP NFs for the fabrication of electrochemical sensors. In our experiments, PU-MWCNT-AgNP NFs were directly electrospun onto the surface of a polished GCE, and the performance of the NF-modified GCE for $\mathrm{H}_{2} \mathrm{O}_{2}$ sensing was investigated. ${ }^{8}$

The experimental results show that pure electrospun PU NFmodified GCE shows no apparent redox processes. After modified with electrospun PU-MWCNT NFs, the diffused current increased clearly because MWCNTs have a catalytically active surface, and therefore they can increase the active surface area of the modified electrode. Similar to the pure PU NF-modified GCE, no obvious redox current peaks appear in the CV of PUMWCNT-modified GCE either. For the PU-Ag NPs NF-modified GCE, a large current response and a broad reduction peak from -0.65 to $-0.4 \mathrm{~V}$ were observed due to the reduction of $\mathrm{H}_{2} \mathrm{O}_{2}$. The presented $\mathrm{CV}$ results indicate that the PU-MWCNT-Agmodified GCE has better electrocatalytic activity than either PU-MWCNT or PU-Ag modified GCE toward the reduction of 
$\mathrm{H}_{2} \mathrm{O}_{2}$, which confirms the synergistic effect of MWCNTs and AgNPs. PU-MWCNT-AgNP-modified GCE reveals a linear response to $\mathrm{H}_{2} \mathrm{O}_{2}$. The biosensor has a linear detection range from 0.5 to $30 \mathrm{mM}(R=0.9999)$, and possesses a detection limit of $18.6 \mu \mathrm{M}(S / N=3)$ with a sensitivity of $160.6 \mu \mathrm{A} \mathrm{mM}^{-1} \mathrm{~cm}^{-2}$.

In a further study, we fabricated PVDF-MWCNT-PtNP nanofibrous membrane by ES and utilized the membrane for biosensors of $\mathrm{H}_{2} \mathrm{O}_{2}$ and glucose. ${ }^{9}$ The nonenzymatic amperometric biosensor has highly stable and sensitive, and selective detection of $\mathrm{H}_{2} \mathrm{O}_{2}$ and glucose.

\section{Conclusions and future perspectives}

The past decade years have witnessed significant progresses of ES technique to fabricate functional nanomaterials for various applications. There is no doubt that ES has become one of the most powerful techniques for preparing diverse nanostructured materials and highly sensitive sensors in the future. In this review, we present a detailed progress report on how to applying ES technique to create polymer NFs filled with MNPs and CNTs, as well as how to put the fabricated nanofibrous materials for electrochemical sensors and biosensors. Essential studies, nevertheless, are still required and many challenges have to be faced. More experimental studies and theoretical modeling are required in order to achieve a better control over the size and morphology of electrospun nanomaterials.

Electrospun nanofibrous materials filled with MNPs and CNTs will have other potential applications in solar cells, batteries, hydrogen storage, environmental protection, and tissue engineering.

\section{Acknowledgements}

The authors gratefully acknowledge the financial supports from the Fundamental Research Funds for the Central Universities (project no. ZZ1307).

\section{Notes and references}

1 A. Formhals, Process and apparatus for preparing artificial threads, US Pat. no. 1975504, 1934.

2 H. R. Darrell and C. Iksoo, Nanotechnology, 1996, 7, 216.

3 L. Cao, M. Dong, A. Zhang, Y. Liu, W. Yang, Z. Su and X. Chen, Polym. Eng. Sci., 2013, 53, 2674-2682.

4 L. Cao, D. Su, Z. Su and X. Chen, Ind. Eng. Chem. Res., 2014, 53, 2308-2317.

5 L. Cao, D. Su, Z. Su and X. Chen, Chin. J. Polym. Sci., 2014, 53, 2308-2317.

6 Z. Su, J. Li, Q. Li, T. Ni and G. Wei, Carbon, 2012, 50, 56055617.

7 Z. Su, J. Li, Z. Ouyang, M. M. Arras, G. Wei and K. D. Jandt, RSC Adv., 2014, 4, 14833-14839.

8 Z. Ouyang, J. Li, J. Wang, Q. Li, T. Ni, X. Zhang, H. Wang, Q. Li, Z. Su and G. Wei, J. Mater. Chem. B, 2013, 1, 24152424.
9 P. Zhang, X. Zhao, X. Zhang, Y. Lai, X. Wang, J. Li, G. Wei and Z. Su, ACS Appl. Mater. Interfaces, 2014, 6, 7563-7571.

10 M. B. Bazbouz and G. K. Stylios, Eur. Polym. J., 2008, 44, 1-12.

11 Q. Du, D. R. Harding and H. Yang, Polymer, 2013, 54, 67526759.

12 J. Yu, Y. Qiu, X. Zha, M. Yu, J. Yu, J. Rafique and J. Yin, Eur. Polym. J., 2008, 44, 2838-2844.

13 S. Soliman, S. Pagliari, A. Rinaldi, G. Forte, R. Fiaccavento, F. Pagliari, O. Franzese, M. Minieri, P. Di Nardo, S. Licoccia and E. Traversa, Acta Biomater., 2010, 6, 1227-1237.

14 F.-L. Zhou, P. L. Hubbard, S. J. Eichhorn and G. J. M. Parker, Polymer, 2011, 52, 3603-3610.

15 X. Lu, X. Bian, G. Nie, C. Zhang, C. Wang and Y. Wei, J. Mater. Chem., 2012, 22, 12723-12730.

16 A. Greiner and J. Wendorff, Adv. Polym. Sci., 2008, 219, 107171.

17 J. D. Schiffman and C. L. Schauer, Polym. Rev., 2008, 48, 317-352.

18 S. Agarwal, J. H. Wendorff and A. Greiner, Polymer, 2008, 49, 5603-5621.

19 D. Yang, X. Niu, Y. Liu, Y. Wang, X. Gu, L. Song, R. Zhao, L. Ma, Y. Shao and X. Jiang, Adv. Mater., 2008, 20, 47704775.

20 D. Yang, X. Liu, Y. Jin, Y. Zhu, D. Zeng, X. Jiang and H. Ma, Biomacromolecules, 2009, 10, 3335-3340.

21 Y. Liu, Y. Sun, H. Yan, X. Liu, W. Zhang, Z. Wang and X. Jiang, Small, 2012, 8, 676-681.

22 W. Chen, S. He, W. Pan, Y. Jin, W. Zhang and X. Jiang, Chem. Mater., 2010, 22, 6212-6214.

23 C. Li, E. T. Thostenson and T.-W. Chou, Compos. Sci. Technol., 2008, 68, 1227-1249.

24 J. H. Sung, H. S. Kim, H.-J. Jin, H. J. Choi and I.-J. Chin, Macromolecules, 2004, 37, 9899-9902.

25 S. H. Yoon, H.-J. Jin, M.-C. Kook and Y. R. Pyun, Biomacromolecules, 2006, 7, 1280-1284.

26 M. Kang, S. J. Myung and H.-J. Jin, Polymer, 2006, 47, 39613966.

27 J. S. Im, J. Yun, J. G. Kim, T.-S. Bae and Y.-S. Lee, Appl. Surf. Sci., 2012, 258, 2219-2225.

28 K. M. Manesh, H. T. Kim, P. Santhosh, A. I. Gopalan and K.-P. Lee, Biosens. Bioelectron., 2008, 23, 771-779.

29 C. B. Jacobs, M. J. Peairs and B. J. Venton, Anal. Chim. Acta, 2010, 662, 105-127.

30 M.-C. Daniel and D. Astruc, Chem. Rev., 2004, 104, 293-346.

31 T. K. Sau and A. L. Rogach, Adv. Mater., 2010, 22, 17811804.

32 R. W. Murray, Chem. Rev., 2008, 108, 2688-2720.

33 Z. Peng and H. Yang, Nano Today, 2009, 4, 143-164.

34 B. Wiley, Y. Sun and Y. Xia, Acc. Chem. Res., 2007, 40, 10671076.

35 Y. Xia, Y. Xiong, B. Lim and S. E. Skrabalak, Angew. Chem., Int. Ed., 2009, 48, 60-103.

36 A. R. Tao, S. Habas and P. Yang, Small, 2008, 4, 310-325.

37 J. Chen, B. Lim, E. P. Lee and Y. Xia, Nano Today, 2009, 4, 81-95. 
38 C. J. Murphy, T. K. Sau, A. M. Gole, C. J. Orendorff, J. Gao, L. Gou, S. E. Hunyadi and T. Li, J. Phys. Chem. B, 2005, 109, 13857-13870.

39 C. M. Cobley, J. Chen, E. C. Cho, L. V. Wang and Y. Xia, Chem. Soc. Rev., 2011, 40, 44-56.

40 S. E. Skrabalak, J. Chen, Y. Sun, X. Lu, L. Au, C. M. Cobley and Y. Xia, Acc. Chem. Res., 2008, 41, 1587-1595.

41 N. Tian, Z.-Y. Zhou, S.-G. Sun, Y. Ding and Z. L. Wang, science, 2007, 316, 732-735.

42 L. Wang and Y. Yamauchi, J. Am. Chem. Soc., 2009, 131, 9152-9153.

43 V. Mazumder, Y. Lee and S. Sun, Adv. Funct. Mater., 2010, 20, 1224-1231.

44 M. J. Mulvihill, X. Y. Ling, J. Henzie and P. Yang, J. Am. Chem. Soc., 2009, 132, 268-274.

45 S. Guo and S. Dong, TrAC, Trends Anal. Chem., 2009, 28, 96109.

46 S. Guo and E. Wang, Anal. Chim. Acta, 2007, 598, 181-192.

47 S. Guo, J. Li, W. Ren, D. Wen, S. Dong and E. Wang, Chem. Mater., 2009, 21, 2247-2257.

48 S. Guo, S. Dong and E. Wang, Small, 2009, 5, 1869-1876.

49 S. Koombhongse, W. Liu and D. H. Reneker, J. Polym. Sci., Part B: Polym. Phys., 2001, 39, 2598-2606.

$50 \mathrm{~J} . \mathrm{Wu}, \mathrm{N}$. Wang, L. Wang, H. Dong, Y. Zhao and L. Jiang, ACS Appl. Mater. Interfaces, 2012, 4, 3207-3212.

51 Y. Jin, D. Yang, D. Kang and X. Jiang, Langmuir, 2009, 26, 1186-1190.

52 D. C. Parajuli, M. P. Bajgai, J. A. Ko, H. K. Kang, M. S. Khil and H. Y. Kim, ACS Appl. Mater. Interfaces, 2009, 1, 750-757.

53 Y. Dror, W. Salalha, R. Avrahami, E. Zussman, A. Yarin, R. Dersch, A. Greiner and J. Wendorff, Small, 2007, 3, 1064-1073.

54 H. Chen, N. Wang, J. Di, Y. Zhao, Y. Song and L. Jiang, Langmuir, 2010, 26, 11291-11296.

55 Y. Zhao, X. Cao and L. Jiang, J. Am. Chem. Soc., 2007, 129, 764-765.

56 H. Dong, N. Wang, L. Wang, H. Bai, J. Wu, Y. Zheng, Y. Zhao and L. Jiang, ChemPhysChem, 2012, 13, 1153-1156.

57 D. Li, G. Ouyang, J. T. McCann and Y. Xia, Nano Lett., 2005, 5, 913-916.

58 J. H. Yu, S. V. Fridrikh and G. C. Rutledge, Adv. Mater., 2004, 16, 1562-1566.

59 Z. Sun, E. Zussman, A. L. Yarin, J. H. Wendorff and A. Greiner, Adv. Mater., 2003, 15, 1929-1932.

60 A. C. Patel, S. Li, J.-M. Yuan and Y. Wei, Nano Lett., 2006, 6, 1042-1046.

61 D. Li, J. T. McCann and Y. Xia, Small, 2005, 1, 83-86.

62 J. T. McCann, D. Li and Y. Xia, J. Mater. Chem., 2005, 15, 735-738.

63 S. Bhaskar and J. Lahann, J. Am. Chem. Soc., 2009, 131, 6650-6651.

64 B. Ding, C. Li, Y. Miyauchi, O. Kuwaki and S. Shiratori, Nanotechnology, 2006, 17, 3685.

65 X. Wang, B. Ding, J. Yu, M. Wang and F. Pan, Nanotechnology, 2010, 21, 055502.
66 W. Wang, S. Itoh, K. Konno, T. Kikkawa, S. Ichinose, K. Sakai, T. Ohkuma and K. Watabe, J. Biomed. Mater. Res., Part A, 2009, 91, 994-1005.

67 L. H. Leung, S. Fan and H. E. Naguib, J. Polym. Sci., Part B: Polym. Phys., 2012, 50, 242-249.

68 M. R. Badrossamay, H. A. McIlwee, J. A. Goss and K. K. Parker, Nano Lett., 2010, 10, 2257-2261.

69 D. Zhang and J. Chang, Nano Lett., 2008, 8, 3283-3287.

70 W. Salalha, Y. Dror, R. L. Khalfin, Y. Cohen, A. L. Yarin and E. Zussman, Langmuir, 2004, 20, 9852-9855.

71 I. S. Chronakis, J. Mater. Process. Technol., 2005, 167, 283293.

72 T. Maitra, S. Sharma, A. Srivastava, Y.-K. Cho, M. Madou and A. Sharma, Carbon, 2012, 50, 1753-1761.

73 M. J. Kim, J. Lee, D. Jung and S. E. Shim, Synth. Met., 2010, 160, 1410-1414.

74 G. Mathew, J. Hong, J. Rhee, H. Lee and C. Nah, Polym. Test., 2005, 24, 712-717.

75 Y.-l. Dai, J.-f. Dai, Y.-b. Sun, X. Li, P. Zhao, Q. Wang and W.-x. Li, Carbon, 2013, 60, 563.

76 L. D. Tijing, C.-H. Park, W. L. Choi, M. T. G. Ruelo, A. Amarjargal, H. R. Pant, I.-T. Im and C. S. Kim, Composites, Part B, 2013, 44, 613-619.

77 H. Chen, Z. Liu and P. Cebe, Polymer, 2009, 50, 872-880.

78 J. J. Ge, H. Hou, Q. Li, M. J. Graham, A. Greiner, D. H. Reneker, F. W. Harris and S. Z. D. Cheng, J. Am. Chem. Soc., 2004, 126, 15754-15761.

79 M. Kang, P. Chen and H.-J. Jin, Curr. Appl. Phys., 2009, 9, S95-S97.

80 R. Sen, B. Zhao, D. Perea, M. E. Itkis, H. Hu, J. Love, E. Bekyarova and R. C. Haddon, Nano Lett., 2004, 4, 459464.

81 S.-H. Park, H.-R. Jung, B.-K. Kim and W.-J. Lee, J. Photochem. Photobiol., A, 2012, 246, 45-49.

82 G. M. Bayley and P. E. Mallon, Polymer, 2012, 53, 55235539.

83 J. Choi, D. W. Park and S. E. Shim, Synth. Met., 2012, 162, 1513-1518.

84 J. Choi, E. J. Park, D. W. Park and S. E. Shim, Synth. Met., 2010, 160, 2664-2669.

85 L. Han, A. L. Andrady and D. S. Ensor, Sens. Actuators, B, 2013, 186, 52-55.

86 K. M. Manesh, P. Santhosh, A. Gopalan and K.-P. Lee, Anal. Biochem., 2007, 360, 189-195.

87 J. Song, M. Chen, V. R. Regina, C. Wang, R. L. Meyer, E. Xie, C. Wang, F. Besenbacher and M. Dong, Adv. Eng. Mater., 2012, 14, B240-B246.

88 K. Müller, J. F. Quinn, A. P. R. Johnston, M. Becker, A. Greiner and F. Caruso, Chem. Mater., 2006, 18, 23972403.

89 B. Carlberg, L.-L. Ye and J. Liu, Small, 2011, 7, 3057-3066.

90 X. Fang, H. Ma, S. Xiao, M. Shen, R. Guo, X. Cao and X. Shi, J. Mater. Chem., 2011, 21, 4493-4501.

91 H. Dong, D. Wang, G. Sun and J. P. Hinestroza, Chem. Mater., 2008, 20, 6627-6632.

92 D. M. Dotzauer, J. Dai, L. Sun and M. L. Bruening, Nano Lett., 2006, 6, 2268-2272. 
93 L. Ouyang, D. M. Dotzauer, S. R. Hogg, J. Macanás, J.-F. Lahitte and M. L. Bruening, Catal. Today, 2010, 156, 100-106.

94 H. Zhu, M. Du, M. Zhang, P. Wang, S. Bao, Y. Fu and J. Yao, Sens. Actuators, B, 2013, 185, 608-619.

95 L. Zhang, X. Gong, Y. Bao, Y. Zhao, M. Xi, C. Jiang and H. Fong, Langmuir, 2012, 28, 14433-14440.

96 W. Jia, L. Su and Y. Lei, Biosens. Bioelectron., 2011, 30, 158164.

97 H. Zhang, J. Huang, H. Hou and T. You, Electroanalysis, 2009, 21, 1869-1874.

98 Y. Liu, H. Teng, H. Hou and T. You, Biosens. Bioelectron., 2009, 24, 3329-3334.

99 P. Ramakrishnan and S. Shanmugam, Electrochim. Acta, 2014, 125, 232-240.

100 M. Zhao, X. Wang, L. Ning, J. Jia, X. Li and L. Cao, Sens. Actuators, B, 2011, 156, 588-592.

101 E. Formo, M. S. Yavuz, E. P. Lee, L. Lane and Y. Xia, J. Mater. Chem., 2009, 19, 3878.
102 Q. Guo, D. Liu, X. Zhang, L. Li, H. Hou, O. Niwa and T. You, Anal. Chem., 2014, 86, 5898-5905.

103 J. Huang, Y. Liu, H. Hou and T. You, Biosens. Bioelectron., 2008, 24, 632-637.

104 Y. Liu, L. Zhang, Q. Guo, H. Hou and T. You, Anal. Chim. Acta, 2010, 663, 153-157.

105 L. Zhang, X. Wang, Y. Zhao, Z. Zhu and H. Fong, Mater. Lett., 2012, 68, 133-136.

106 J. Huang, D. Wang, H. Hou and T. You, Adv. Funct. Mater., 2008, 18, 441-448.

107 Y. Liu, D. Wang, L. Xu, H. Hou and T. You, Biosens. Bioelectron., 2011, 26, 4585-4590.

108 A. Devadoss, H. Han, T. Song, Y. P. Kim and U. Paik, Analyst, 2013, 138, 5025-5030.

109 J. Wang, H.-B. Yao, D. He, C.-L. Zhang and S.-H. Yu, ACS Appl. Mater. Interfaces, 2012, 4, 1963-1971.

110 S. Xiao, M. Shen, R. Guo, Q. Huang, S. Wang and X. Shi, J. Mater. Chem., 2010, 20, 5700.

111 S. Hwang, S. Y. Noh, H. Kim, M. Park and H. Lee, Thin Solid Films, 2014, 562, 445-450. 